\title{
INFLUENCE OF ANTIBACTERIAL COPPER GLASS PARTICLES ON SURFACE AND MECHANICAL PROPERTIES OF FLOWABLE COMPOSITES
}

\author{
Dalia A. Abuelenain*
}

\begin{abstract}
Copper oxide containing phosphate glasses showed an antibacterial action against streptococcus sanguis, streptococcus mutans and staphylococcus epidermidis. This study aimed to investigate the effect of adding copper glass particles (0- $25 \mathrm{wt} \%$ ) into flowable composites (Filtek Z350XT flowable and Fusio liquid dentin dental flowable) to induce antibacterial properties. Surface (contact angle and Vicker hardness number) and mechanical (flexure strength, strain and modulus) properties of modified composites have been tested throughout this study; the antibacterial action will be tested in the future. The results showed that both surface and mechanical properties were dependent on the original composite as well as the added filler content. Lower contact angles, indicating higher wettability of the composites, observed with the higher loading of copper glass particles in both resin composites; this high wettability was obvious with Fusio flowable composites. This would be beneficial in bacterial adhesion to the composite surface and hence the expected antibacterial activity of copper glass against the adherent bacteria during biofilm formation. Surface hardness was not negatively affected by adding copper glass particles, except at higher loading levels (25 wt\%) particularly when added to Z350 composites. This could indicate that the copper glass at low wt $\%$ had no adverse effect on monomer conversion. Generally, the rigidity (indicated by flexure modulus) and strain $\%$ of both composites were not affected by the presence of copper glass particles. Finally, it can be concluded that addition of low wt $\%$ of copper glass particles (up to $10 \mathrm{wt} \%$ ) could provide a restorative material with antibacterial action without compromising their surface and mechanical properties. Addition of high wt $\%$ of copper glass to Fusio flowable in particular could be beneficial in producing a more hydrophilic material that could potentially encourage bacterial adhesion and hence a significant antibacterial action of copper glass against adherent bacteria will be expected.
\end{abstract}

\section{INTRODUCTION}

The ultimate goal of restorative dentistry is to replace damaged dental tissues for restoring function and esthetics as well as to prevent the recurrent decays of restored tissues. The most widely used esthetic direct restorative resin materials in current decades are satisfying the first goal, but they are

\footnotetext{
* King Abdulaziz University Faculty of Dentistry, Operative Dentistry Department, Biomaterials Division, Jeddah, Saudi Arabia.
} 
mostly bioinert to prevent the recurrent decays ${ }^{(1)}$. This has therefore been documented as the main cause of failure in resin restorations ${ }^{(2)}$.

Two main mechanisms are needed to prevent secondary caries; suppressing biofilm acids and promoting remineralization ${ }^{(1)}$. Researchers are diligent to modify the current resin restorative materials with antibacterial elements to prevent caries under dental restorations at the same time to allow for hard tissue remineralization without the need of several materials application. For this purpose, bioactive resins with anti-caries properties were developed and a new generation of bioactive/therapeutic materials has been introduced $^{(1)}$. Several materials with antibacterial actions were considered as modifiers for dental restorative materials ${ }^{(1,3-11)}$. Examples of these materials include zinc methacrylate monomer, silver particle, titanium dioxide, calcium phosphate, zinc oxide and copper oxide.

Silver particles known to have antimicrobial activity against Escherichia coli and Streptococcus mutans were added to resins in previous investigations ${ }^{(1,6)}$. The silver nano- particles greatly reduced biofilm growth without negatively affecting the material's color and bond strength. Incorporation of calcium phosphate particles with antibacterial activity into resins released calcium and phosphate ions and re-mineralized carious lesions ${ }^{(12)}$. However, composites containing calcium phosphate particles were mechanically weak and cannot be handled as a restorative materials ${ }^{(1)}$.

Fluoride is a dual element, that can inhibit bacterial metabolism and enhance tooth remineralization ${ }^{(1)}$. Topical fluoride application will provide remineralization of infected and affected dental tissues with the antibacterial action when applied as a glass ionomer restoration; this bacterial inhibition will diminish if fluoride is incorporated in resin based restorations ${ }^{(13)}$. Regardless of the antibacterial action of fluoride, it was not proven that fluoride releasing restorative materials will reduce the incidence of recurrent caries ${ }^{(14)}$.

In several investigations ${ }^{(7,15)}$, Copper oxide $(\mathrm{CuO})$ delivered by phosphate based glass fibers, showed antibacterial action against streptococcus sanguis, the main cariogenic bacteria streptococcus mutans (16) and staphylococcus epidermidis. Furthermore, $\mathrm{CuO}$ particles were proved to be more potent against streptococcus mutans, compared to zinc oxide particles as confirmed by Ramazanzadeh et al ${ }^{(7)}$. Therefore, adding $\mathrm{CuO}$ particles to restorative materials may lower the risk of bacterial accumulation on restorative materials and then reducing the potential of recurrent decays in restored teeth.

Incorporation of bioactive elements into dental resins are still within its experimental stage and it needs further investigations. The influence of added antibacterial elements into resin materials on surface and mechanical properties is an essential factor to determine the applicability of these restorative materials. Therefore, the aim of the present study was to evaluate the effect of adding copper glass particles to flowable composites on contact angle, surface hardness, flexure strength and modulus.

\section{MATERIALS AND METHODS}

Composite materials used in the present study (Filtek Z350 XT flowable, Fusio Liquid dentin) are presented in table 1. The filler used in this study was copper containing phosphate based glass particles of approximately $60-200 \mathrm{~mm}$ in diameter. These particles have the composition of $50 \mathrm{~mol} \%$ $\mathrm{P}_{2} \mathrm{O}_{5}, 30 \mathrm{~mol} \% \mathrm{CaO}, 10 \mathrm{~mol} \% \mathrm{NaO}$ and $10 \mathrm{~mol} \%$ $\mathrm{Cu}^{(15)}$. Copper glass was added at $0,1,5,10$ and 25 wt $\%$ to each composite material; this resulted in 10 experimental groups, 5 groups ( $\mathrm{n}=3$ for each group) for each composite material. Samples were coded as $\mathrm{Z} 350,1 \% \mathrm{Cu} \mathrm{Z} 350,5 \% \mathrm{Cu} \mathrm{Z} 350,10 \% \mathrm{Cu} \mathrm{Z} 350$ and $25 \% \mathrm{Cu} \mathrm{Z350.} \mathrm{Fus,} 1 \% \mathrm{Cu}$ Fus, 5\%Cu Fus, 10\% Cu Fus, 25\%Cu Fus. 
TABLE (1) Details of restorative resin materials used in the study.

\begin{tabular}{|l|l|l|l|}
\hline Resin material & Manufacturer & Composition & Filler loading \\
\hline $\begin{array}{l}\text { Filtek Z350 XT flowable } \\
\text { composite }\end{array}$ & $3 \mathrm{M}$ ESPE & $\begin{array}{l}\text { Organic: bis-GMA, UDMA, TEGDMA, and bis-EMA(6) } \\
\text { resins, } \\
\text { In-organic: a combination of silica, zirconia, and } \\
\text { zirconia/silica cluster filler }\end{array}$ & $\begin{array}{l}78.5 \% \text { by weight } \\
63.3 \% \text { by volume }\end{array}$ \\
\hline $\begin{array}{l}\text { Fusio Liquid dentin } \\
\text { dental flowable composite }\end{array}$ & PENTRON & $\begin{array}{l}\text { Organic: UDMA, TEGDMA, HEMA, 4-MET, In-organic: } \\
\text { Silane treated barium glass, Silica. }\end{array}$ & $\begin{array}{l}65 \% \text { by weight } \\
52 \% \text { by volume }\end{array}$ \\
\hline
\end{tabular}

\section{Contact Angle Measurements}

Discs of $10 \mathrm{~mm}$ diameter and $2 \mathrm{~mm}$ height were prepared using a split Teflon mold $(n=3)$. Experimental materials were backed into the Teflon mold and sandwiched between two celluloid strips and glass slides. Samples were then light cured from each side for 20 seconds using LED light (3M ELEBAR) with a wave length range between 430$480 \mathrm{~nm}$ and light intensity of $1200 \mathrm{Mw} / \mathrm{cm}^{2}$. Three samples from each composition were subjected to wettability measurement using a drop shape analyzer(Kruss). Contact angle was performed using distilled water as the test liquid. Drop Shape Analysis [DSA4] software was used to measure the contact angle.

\section{Vickers Hardness Number}

Discs of $10 \mathrm{~mm}$ diameter and $2 \mathrm{~mm}$ height were prepared using a split Teflon mold $(n=3)$ as described above. Vickers hardness numbers were determined using a micro-hardness tester (Micromet 6040, Buehler, USA) under a load of $100 \mathrm{~g}$ and dwell time of 10 seconds. Three readings were recorded for each surface; the hardness number was presented as the average of these readings. Relative hardness (ratio of bottom to top hardness) for each experimental group was also recorded.

\section{Three-point Bending Test}

Thirty specimens were prepared $(n=3$ for each composition), by backing composite into a rectangular split Teflon mold $\left(2 \times 2 \times 25 \mathrm{~mm}^{3}\right)$ according to ISO 4049 specification for polymerbased restorations ${ }^{(17)}$. Molds with composite materials were sandwiched between two celluloid strip and glass slides and tightened at both ends using paper clamps. Each specimen was then subjected to 4 overlapping 40 seconds curing cycles from one side. The cured specimen was then removed from the mold; excess materials were removed with a sharp scalpel. The prepared specimens were then stored for 24 hours in dry container at room temperature $\left(22^{\circ} \mathrm{C} \pm 1\right)$ prior to testing. Before flexure testing, dimension of each specimen was determined with a micrometer accurate to $0.01 \mathrm{~mm}$. The threepoint bending test was carried out using the Instron testing machine (Instron 5944, USA) with a span of $20 \mathrm{~mm}$ at a crosshead speed of $0.25 \mathrm{~mm} / \mathrm{min}$ and $2 \mathrm{KN}$ load. The flexure strength (MPa), modulus $(\mathrm{GPa})$ and strain at break $(\%)$ were measured using Bluehill 3 software.

\section{Statistical Analysis}

The data were collected and analyzed using oneway ANOVA and Tukey's post hoc test to delineate areas of significance. Data collection and analysis was done using SPSS (Version 20.0, IBM, and New York, USA). 


\section{RESULTS}

\section{Contact Angle Measurements}

One way ANOVA test of contact angle mean values and standard deviations revealed a significant difference between groups $(p<0.001)$. There was no significant difference in contact angle tested with distilled water between Z350 flowable composite groups modified with $0 \%, 1 \%, 5 \%$ and $10 \%$ copper glass particle $(85 \pm 6,86 \pm, 84 \pm 1$ and $81 \pm 7$, respectively) ( $\mathrm{P}>0.05)$. However, 25\% copper glass modified Z350 composite showed a significantly lower contact angle $(71 \pm 8)$ compared to the Z350 group modified with $1 \%$ copper glass particles $(\mathrm{p}=0.038)-$ Fig. 1 .

On the other hand, $10 \%$ and $25 \%$ copper glass modified Fusio liquid dentin composite, had a statistically significant lower contact angle $(61 \pm 5$, $65 \pm 5$ ) compared to $0 \%, 1 \%$, and $5 \%$ copper glass modified Fusio composite groups $(77 \pm 4,79 \pm 1$, $77 \pm 6)(\mathrm{p}<0.05)-$ Fig. 1.

Comparing the two composite materials revealed that $10 \%$ and $25 \%$ copper glass modified Fusio liquid dentin composite had a statistically significant lower contact angle values compared to all other experimental groups $(\mathrm{p}<0.05)$ - Fig. 1

\section{Vicker Hardness Number}

Regarding surface hardness, a significant difference between experimental groups of Z350 $(p<0.05)$ were observed. However, all groups of Fusio composite material surface hardness was not affected significantly by adding copper glass particles $(42 \pm 5,38 \pm 6,43.5 \pm 3,37 \pm 1$ and $35 \pm 2$, respectively) $\quad(\mathrm{p}>0.05)$. Z350 groups surface hardness showed that, adding $25 \%$ copper glass to Z350 composite resulted in a significantly lower surface harness $(31 \pm 1)$ compared to the $0 \%, 1 \%$, $5 \%$ and $10 \%$ copper glass modified groups of Z350 composite materials $(47 \pm 1,43.5 \pm 0.1,41 \pm 2$ and $55.5 \pm 14)(\mathrm{p}<0.05)-$ Fig. 2
Mean values of relative hardness were not affected significantly in both materials after adding the experimental amounts of cupper particles $(\mathrm{p}=0.233)-$ Fig. (3)

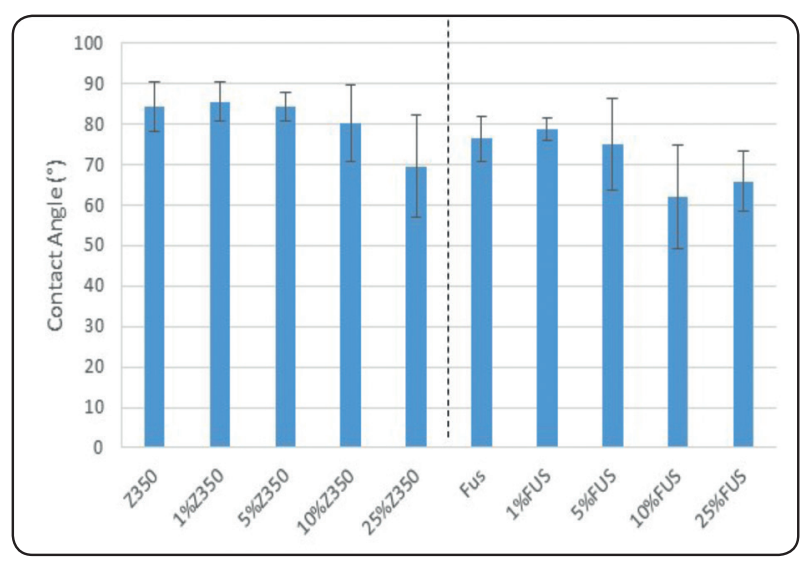

Fig. (1) Contact angle $\left({ }^{\circ}\right)$ of tested materials.

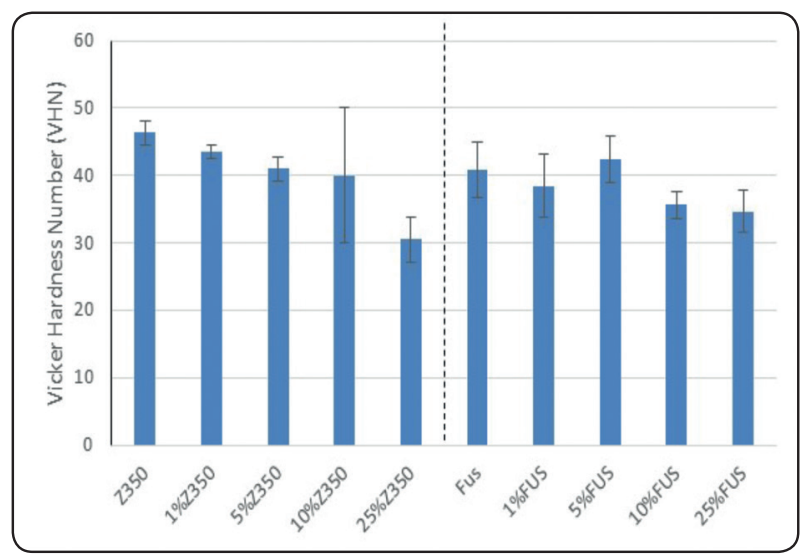

Fig. (2) Vicker hardness number of tested materials.

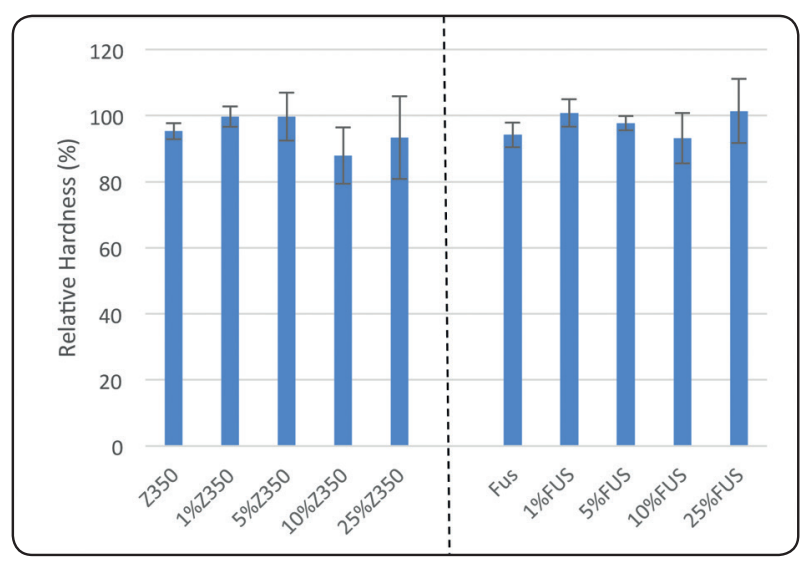

Fig. (3) Relative hardness (\%) hardness of tested materials. 


\section{Three-point Bending Test}

Analysis of the mean strain (\%) values showed that the addition of copper glass produced no significant change in strain \% of Z350 flowable composites. On the contrary, a significant reduction was observed in strain \% of Fusio flowable composites - Fig. 4.

Analysis of mean flexure strength values showed a significant difference between different experimental groups $(\mathrm{p}<0.05) . \mathrm{Z} 350$ experimental groups showed a significant drop in flexure strength after adding $1 \%$ copper glass compared to the $0 \%$ copper glass modified Z350 ( $\mathrm{p}<0.05)$. In addition, the $5 \%, 10 \%$ and $25 \%$ copper glass modified Z350 groups $(61 \pm 4,49 \pm 11$ and $39 \pm 7 \mathrm{MPa}$ respectively) were significantly lower than the $0 \%$ and $1 \%$ copper glass-modified Z350 (112 \pm 5 and $76 \pm 19 \mathrm{MPa}$ respectively) (p<0.05) - Fig. 4 .

Different results were observed in Fusio experimental groups, in which $10 \%$ and $25 \%$ copper glass modified Fusio $(65 \pm 9$ and $60 \pm 2 \mathrm{MPa}$ respectively) had a statistically significant drop in flexure strength compared to $0 \%, 1 \%$ and $5 \%$ copper glass modified Fusio material $(99 \pm 11,74 \pm 14$ and $71 \pm 7$ MPa respectively) $(\mathrm{p}<0.5)$, while there was no significant difference between the former three experimental groups $(\mathrm{p}>0.05)$ - Fig. 4.

Analysis of modulus of elasticity mean values showed a significant difference between groups ( $\mathrm{p}<$ $0.5)$. $25 \%$ copper glass modified Z350 $(3.3 \pm 1 \mathrm{Gpa})$ was significantly lower than the $0 \%, 1 \%, 5 \%$, and $10 \%$ copper glass modified Z350 experimental groups $(6 \pm 0.7,5 \pm 0.5,5 \pm 0.6$ and $6 \pm 0.5 \mathrm{GPa}$ respectively) $(\mathrm{p}<0.05)$. On the other hand, there was no significant difference in modulus values between $0 \%, 1 \% 5 \%, 10 \%$ and $25 \%$ copper glass modified Fusio composite materials $(6 \pm 0.5,6 \pm 0.2$, $7 \pm 0.5,7 \pm 0.5,6 \pm 0.5$ Gpa respectively) $(\mathrm{p}>0.05)-$ Fig. 4.

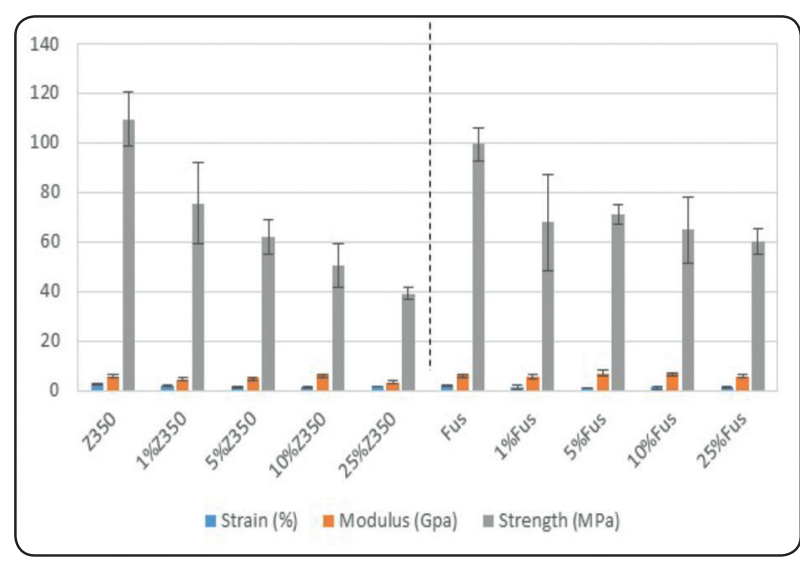

Fig. (4) Flexure strain (\%), strength (MPa) and Modulus (GPa) of tested materials.

\section{DISCUSSION}

Several investigations examined the influence of copper glass particles as antibacterial/ anticariogenic element when added to dental resin materials ${ }^{(3-5,7)}$. In an old study by Bapna etal (1988), copper oxide was not effective as antibacterial agent againest streptocuccos mutans when compared to silver compounds ${ }^{(5)}$. However in a more recent study ${ }^{(4)}$, the application of copper modified varnish had anticariogenic effects to root surfaces treated with this varnish when compred to the negative control that received no treatment. In another study by Argueta-figueroa et al $^{(3)}$, the incorporation of copper nanoparticles into the orthodontic resin adhesives showed a bacteriocidal effect againest $S$. aureus, E. coli and S. mutans.

In the present study, copper glass particles were added to two types of flowable composites to induce the antibacterial action, but this study aimed to investigate the influence of copper glass particles on the surface and mechanical properties of dental resins. Testing the antibacterial action of these composites however will be carried out in the future.

Results of the present work showed that, the effect of copper glass particles depends on the type of composites to which this filler was added as well 
as the percent of the added particles. Fusio liquid dentin, used as a self-adhesive dentin replacement material, showed promising results with lower loading levels of copper glass particles. The hardness was not negatively affected by adding the copper glass particles. However, the flexure strength was only significantly reduced when copper glass particles were added at high percentage (10\% and 25 wt \%). At this high level of copper glass, the wettability was significantly increased; at low level of filler loading ( $1 \%$ and 5 wt \%), however, the flexure strength and wettability were not significantly affected. There was no reduction in flexure modulus at any copper glass loading levels.

However, for Filtek Z350 flowable composite, addition of copper glass particles resulted in a significant drop in flexure strength at all loading levels of copper glass. The reduction in flexure modulus and hardness was only observed with the highest filler loading (25 wt \%). The wettability however was significantly increased at $25 \mathrm{wt} \%$ filler addition.

Therefore, copper glass modification of Fusio liquid dentin at $1 \%$ and $5 \%$ loading level may result in a restorative bacteriostatic material that can be clinically applied without compromizing the material's surface or mechanical properties. On the countrary, adding copper glass particles to Z350 composite resulted in a significant drop in flexure strength even at the lowest amount. This might be inferred to the lower filler content of Fusio liquid dentin ( $65 \%$ by weight) compared to the filler loading of Z350 (78.5\% by weight), that permitted the addition of copper glass up to $10 \mathrm{wt} \%$ without reducing the mechanical or surface properties of Fusio Liquid dentin.

Relative hardness as an indication of degree of monomer conversion ${ }^{(18,19)} 2$ - and 3-mm thick samples of three types of resin composite: an anterior microfill, an anterior hybrid and a posterior hybrid, all having differing filler size and loading but similar shade (A2 was not affected by adding copper glass particles in both materials at all loading levels. This might indicate that the addition of copper glass particles did not affect the penetration of light beam within the resin material. Therefore the degree of monomer conversion was not affected by the presence of copper glass particles.

Results of the present work showed that, higher loading levels of added particles will compromise all tested mechanical and surface properties in both tested materials. These results coincide with other investigation ${ }^{(20)}$ in which the incorporation of zinc oxide antibacterial particles into the resin matrix of flowable composite enhanced its mechanical property in low percentages up to a threshold beyond which, more added particles negatively affected the mechanical properties.

This might be explained as the higher loading with the antibacterial particles will result in reduction of the amount of the main bulk of the composite material and increasing flaws and defects within the material deteriorating the surface and mechanical properties.

\section{CONCLUSION}

1- The influence of copper glass particles on surface and mechanical properties of flowable composite materials is material dependent.

2- Wettability of tested composites, as indicated by the contact angle, was not significantly affected by the addition of copper glass except only at 25 $\mathrm{wt} \%$ that produced relatively more hydrophilic materials. Hydrophilic restorative materials could be beneficial in helping bacterial adhesion and hence a more antibacterial action could be produced by the incorporated copper glass.

3- Surface hardness was only significantly reduced by adding $25 \mathrm{wt} \%$ copper glass particles to Z350 composites. This indicated that copper 
glass particles at low wt $\%$ had no adverse effect on degree of monomer conversion.

4- Addition of copper glass produced a significant reduction in flexure strength of Z350 flowable composites, but this reduction was only observed particularly with Fusio flowable composites when copper glass was added at high $\mathrm{wt} \%(10 \& 25)$.

5- Addition of copper glass produced no significant change in strain \% of Z350 flowable composites. On the contrary, a significant reduction was observed in strain \% of Fusio flowable composites.

6- Addition of copper glass produced no significant change in modulus of both Z350 and Fusio flowable composites.

7- Finally, it can be concluded that addition of low $\mathrm{wt} \%$ of copper glass particles (up to $10 \mathrm{wt} \%$ ) could provide a restorative material with antibacterial action without compromising their surface and mechanical properties. Addition of high wt $\%$ of copper glass to Fusio flowable in particular could be beneficial in producing a more hydrophilic material that could potentially encourage bacterial adhesion and hence a significant antibacterial action of copper glass against adherent bacteria will be expected.

\section{ACKNOWLEDGMENT}

The author would like to acknowledge with gratitude Prof. Ensanya A. Abou Neel for providing the copper glass particles used in the present work, and for her advice and efforts during the conduction and writing of this research. The author would also like to acknowledge the "Advanced Technology Dental Research Laboratory" at King Abdulaziz University, Faculty of Dentistry.

\section{CONFLICT OF INTEREST}

The author declares that there is no conflict of interest regarding the publication of this paper.

\section{REFERENCES}

1. Cheng L, Zhang K, Zhang N, Melo MAS, Weir MD, Zhou XD, et al. Developing a New Generation of Antimicrobial and Bioactive Dental Resins. J Dent Res . 2017;96(8):85563.

2. MG RA-KA, P S, PR S, Davis D. Direct composite resin fillings versus amalgam fillings for permanent or adult posterior teeth ( Review ). Cochrane Database Syst Rev 2014, 2014;(3).

3. Argueta-figueroa L, Scougall-vilchis RJ, Morales-luckie RA. An evaluation of the antibacterial properties and shear bond strength of copper nanoparticles as a nanofiller in orthodontic . Aust Orthod J. 2015;31(May):42-8.

4. Thneibat A, Fontana M, Cochran MA, Gonzalez-Cabezas C, Moore BK, Matis BA, et al. Anticariogenic and antibacterial properties of a copper varnish using an in vitro microbial caries model. Oper Dent. 2008;33(2):142-8.

5. Bapna MS, Murphy R, Mukherjee S. Inhibition of bacterial colonization by antimicrobial agents incorporated into dental resins. J Oral Rehabil. 1988;15(5):405-11.

6. Fenno JC, Boccaccini AR. Fabrication and characterization of bioactive and antibacterial composites for dental applications. Acta Biomater . 2014;10(8):3723-32.

7. Ramazanzadeh B, Jahanbin A, Yaghoubi M, Shahtahmassbi N, Ghazvini K, Shakeri M, et al. Comparison of Antibacterial Effects of $\mathrm{ZnO}$ and $\mathrm{CuO}$ Nanoparticles Coated Brackets against Streptococcus Mutans. J Dent . 2015;16(3):200-5.

8. Melo MAS, Cheng L, Zhang K, Weir MD, Rodrigues LKA, Xu HHK. Novel dental adhesives containing nanoparticles of silver and amorphous calcium phosphate. In: Dental Materials. 2013. p. 199-210.

9. Melo MAS, Cheng L, Weir MD, Hsia RC, Rodrigues LKA, $\mathrm{Xu}$ HHK. Novel dental adhesive containing antibacterial agents and calcium phosphate nanoparticles. J Biomed Mater Res - Part B Appl Biomater. 2013;101(1):620-9.

10. Henn S, Nedel F, De Carvalho RV, Lund RG, Cenci MS, Pereira-Cenci T, et al. Characterization of an antimicrobial dental resin adhesive containing zinc methacrylate. J Mater Sci Mater Med. 2011;22(8):1797-802.

11. Mohamed Hamouda I. Current perspectives of nanoparticles in medical and dental biomaterials. J Biomed Res. 2012;26(3):143-51. 
12. Langhorst S.E., O’Donnel J.N.R.1 and SD. In vitro remineralization of enamel by polymeric amorphous calcium phosphate composite: Quantitative micro-radiographic study. Dent Mater. 2009;25(7):884-91.

13. Abcdfg GM, B PJ, Bd JM. Fluoride release and antibacterial activity of selected dental materials Fluoride release and antibacterial activity of selected dental materials. Postep Hig Med Dosw. 2006;60(January):416-20.

14. Wiegand A, Attin T. Review on fluoride-releasing restorative materials - Fluoride release and uptake characteristics , antibacterial activity and ... release and uptake characteristics , antibacterial. Dent Mater. 2007;(April):343-62.

15. Abou Neel EA, Ahmed I, Pratten J, Nazhat SN, Knowles JC. Characterisation of antibacterial copper releasing degradable phosphate glass fibres. Biomaterials. 2005; 26(15):2247-54.

16. Farrugia C, Camilleri J. Antimicrobial properties of conventional restorative filling materials and advances in antimicrobial properties of composite resins and glass ionomer cements - A literature review. Dent Mater. 2015;31(4):e89-99.

17. ISO 4049: 2009. Polymer-based filling, restorative and luting materials Geneva, Switzerland: International Organization for Standardization

18. Bouschlicher MR, Rueggeberg FA, Wilson BM. Correlation of bottom-to-top surface microhardness and conversion ratios for a variety of resin composite compositions. Oper Dent . 2004;29(6):698-704.

19. Abuelenain D, Abou Neel EA, Dharrab A. Surface and Mechanical Properties of Different Dental Composites. Austin J Dent Austin J Dent. 2015;2(2):1019-2.

20. Tavassoli Hojati S, Alaghemand H, Hamze F, Ahmadian Babaki F, Rajab-Nia R, Rezvani MB, et al. Antibacterial, physical and mechanical properties of flowable resin composites containing zinc oxide nanoparticles. Dent Mater . 2013;29(5):495-505. 